\title{
Modeling the stratospheric warming following the Mt. Pinatubo eruption: uncertainties in aerosol extinctions
}

\author{
F. Arfeuille ${ }^{1,2}$, B. P. Luo ${ }^{1}$, P. Heckendorn ${ }^{1}$, D. Weisenstein ${ }^{3}$, J. X. Sheng ${ }^{1}$, E. Rozanov ${ }^{1,4}$, M. Schraner ${ }^{5}$, \\ S. Brönnimann ${ }^{2}$, L. W. Thomason ${ }^{6}$, and T. Peter ${ }^{1}$ \\ ${ }^{1}$ Institute for Atmospheric and Climate Science ETH Zurich, Zurich, Switzerland \\ ${ }^{2}$ Oeschger Centre for Climate Change Research and Institute of Geography, University of Bern, Bern, Switzerland \\ ${ }^{3}$ School of Engineering and Applied Science, Harvard University, Cambridge, MA, USA \\ ${ }^{4}$ Physical-Meteorological Observatory/World Radiation Center, Davos, Switzerland \\ ${ }^{5}$ Federal office of Meteorology and Climatology, Meteoswiss, Zürich, Switzerland \\ ${ }^{6}$ NASA Langley Research Center, Hampton, VA, USA \\ Correspondence to: F. Arfeuille (florian.arfeuille@giub.unibe.ch)
}

Received: 10 December 2012 - Published in Atmos. Chem. Phys. Discuss.: 18 February 2013

Revised: 3 September 2013 - Accepted: 7 October 2013 - Published: 18 November 2013

\begin{abstract}
In terms of atmospheric impact, the volcanic eruption of Mt. Pinatubo (1991) is the best characterized large eruption on record. We investigate here the modelderived stratospheric warming following the Pinatubo eruption as derived from SAGE II extinction data including recent improvements in the processing algorithm. This method, termed SAGE_4 $\lambda$, makes use of the four wavelengths (385, 452,525 and $1024 \mathrm{~nm}$ ) of the SAGE II data when available, and uses a data-filling procedure in the opacity-induced "gap" regions. Using SAGE_4 $\lambda$, we derived aerosol size distributions that properly reproduce extinction coefficients also at much longer wavelengths. This provides a good basis for calculating the absorption of terrestrial infrared radiation and the resulting stratospheric heating. However, we also show that the use of this data set in a global chemistry-climate model (CCM) still leads to stronger aerosol-induced stratospheric heating than observed, with temperatures partly even higher than the already too high values found by many models in recent general circulation model (GCM) and CCM intercomparisons. This suggests that the overestimation of the stratospheric warming after the Pinatubo eruption may not be ascribed to an insufficient observational database but instead to using outdated data sets, to deficiencies in the implementation of the forcing data, or to radiative or dynamical model artifacts. Conversely, the SAGE_ $4 \lambda$ approach reduces the infrared absorption in the tropical tropopause region, result-
\end{abstract}

ing in a significantly better agreement with the post-volcanic temperature record at these altitudes.

\section{Introduction}

The most recent large tropical volcanic eruption was that of Mt. Pinatubo in June 1991 in the Philippines $\left(15^{\circ} \mathrm{N}\right)$. Unlike earlier major volcanic eruptions of the 20th century, Mt. Pinatubo has been relatively well characterized by observations. Several satellite, balloon-borne and ground-based measurements are available during this period (Bluth et al., 1992; Labitzke and McCormick, 1992; McCormick, 1992; Stowe et al., 1992; Thomason, 1992; Minnis et al., 1993; Antuña et al., 2002). However, the peak of the stratospheric aerosol cloud is not well characterized as the observational network was best established in the Northern Hemisphere and less dense in the tropics and Southern Hemisphere, where a large part of the emitted $\mathrm{SO}_{2}$ and resulting sulfate aerosols was transported. An additional problem was that for some limb-viewing instruments measuring in the shortwave, the lower stratosphere became opaque. For instance, during the first year after the Pinatubo eruption, SAGE II measured only above about $23 \mathrm{~km}$ altitude at wavelengths of $1.024 \mu \mathrm{m}$ and shorter. To cope with the regions of missing data, SPARC (2006) provides a "gap-filled" data set spanning the period 1979-2004 using SAGE data amended by 
measurements from lidar ground stations. This SAGE II gapfilled data set provides the most complete and accurate (uncertainty around $10 \%$ outside the gap) global optical characterization of the eruption, even if the quality of this data set in the most perturbed periods is limited, in particular in the tropics, with uncertainties on the order of $50 \%$ in the extinction coefficients in the gap region.

There have been several earlier attempts to create a consistent global stratospheric aerosol data set of the Pinatubo eruption (e.g., Sato et al., 1993; Stenchikov et al., 1998) for climate models. The data set of Stenchikov et al. (1998) provides directly calculated heating rates for modeling studies, while the Sato et al. (1993) "GISS" data set consists of optical depth data for $0.5 \mu \mathrm{m}$ wavelength and effective radii in 4 different altitude ranges and 24 latitude bands derived from SAGE II data. However, these two data sets use outdated versions of the SAGE retrieval algorithm and a very coarse gapfilling procedure (via interpolation of extinction coefficients down to the tropopause).

Stenchikov et al. (1998) used infrared (CLAES-ISAMS) data to fit the effective radius and width of the distribution (assuming a lognormal size distribution with width $\sigma=$ 1.25). However, as we will show below, no systematic comparison with extinction coefficients from HALOE at $3.46 \mu \mathrm{m}$ and 5.26 $\mu \mathrm{m}$ (Russell et al., 1993; Hervig et al., 1995) or ISAMS at $12.1 \mu \mathrm{m}$ (Lambert et al., 1997) was performed to verify the applicability for extinction coefficients in the terrestrial IR, which is a requirement for climate simulations.

Extinction coefficients of HALOE at $3.46 \mu \mathrm{m}$ and $5.26 \mu \mathrm{m}$ are of good quality during the period affected by the Pinatubo eruption (Thomason et al., 2012). ISAMS extinction coefficient uncertainties at $12.1 \mu \mathrm{m}$ for the Equator are on the order of $50 \%$ at $70 \mathrm{hPa}$ and less than $20 \%$ at $45 \mathrm{hPa}$ and above, while for $40^{\circ} \mathrm{N}$, uncertainties are less than $25 \%$ below $45 \mathrm{hPa}$ and close to $50 \%$ at $32 \mathrm{hPa}$ (Lambert et al., 1996).

The accuracy of the solar and infrared extinction coefficients in stratospheric aerosol data sets is an important point because large stratospheric volcanic eruptions in the tropics represent major external forcings to the climate system, and many uncertainties remain in their modeling by chemistry-climate model (CCMs) or general circulation models (GCMs). Simulations exhibit a large range of responses due to model deficiencies and/or uncertainties in the volcanic forcing. Many GCMs/CCMs overestimate the stratospheric warming after volcanic eruptions, and an attribution of this artifact remains difficult because of the large range of optical forcings obtained with different approaches and data sets (SPARC-CCMVal, 2010; Gettelman et al., 2010; Lanzante and Free, 2007).

As noted by Morgenstern et al. (2010), different approaches have been followed among the CCMval-2 (SPARCCCMVal, 2010) models to represent the volcanic forcing. Some models (CAM3.5, GEOSCOM, LMDZrepro, UMSLIMCAT and UMUKCA-UCAM) do not at all model the heating by the aerosol, while ULAQ REF-B1 uses direct
$\mathrm{SO}_{2}$ injections. A third group derives heating rates consistent with prescribed SAD (surface area density) data (CMAM and WACCM) or use the GISS (Sato et al., 1993) data (AMTRAC3, CCSRNIES, MRI, UMETRAC, UMUKCAMETO). These two methods require assumptions on the size distribution, notably through a fixed distribution width. Some models also directly use the precalculated heating rates from Stenchikov et al. (1998), which are based partly on the Sato et al. (1993) extinction data (E39CA and EMAC). The CCM SOCOL, which participated in CCMval-2, was forced by a data set based on SAGE II measurements. All these methods produce large differences in the volcanic aerosol optical properties, making it difficult to compare these models against each other. Finally, it must also be noted that uncertainties in observed/modeled tropopause height may lead climate models to discard part of the heating rates below the tropopause, hence not representing fully the stratospheric forcing of a given aerosol data set.

\section{Methods}

The most elaborate gap-filled SAGE II $1.024 \mu \mathrm{m}$ extinction coefficient record is described by SPARC (2006) (hereafter called SAGE_ASAP). The gaps in the SAGE II measurements, mainly caused by opaqueness directly after the Pinatubo eruption, were filled by means of lidar measurements at Mauna Loa in Hawaii; at Camagüey in Cuba; at Hampton, Virginia (USA); and with backscatter sonde measurements from Lauder, New Zealand. The lidar measurements have been converted to $1.024 \mu \mathrm{m}$ (SAGE II wavelength) (Antuña et al., 2003). The main aerosol cloud was frequently over Mauna Loa $\left(19.54^{\circ} \mathrm{N}\right)$ and Camagüey $\left(21.4^{\circ} \mathrm{N}\right)$, and these values are taken for the tropical region. However, due to the fact that the main aerosol cloud was not always located above the two lidar stations, an erroneous seasonality of the aerosol amount might be present in the compiled data set (SPARC, 2006). The differences between the SAGE V6.0 version used by SPARC (2006) and earlier versions as used by Stenchikov et al. (1998) and Sato et al. (1993) are described in Sect. 3.

To retrieve extinction coefficients (subsequently referred to as "extinctions") in the whole spectral range and subsequently model the stratospheric warming response, the particle size distribution has to be known. During quiescent times the size distribution of stratospheric aerosol is relatively well captured by a simple unimodal lognormal distribution (Wurl et al., 2010). However, after volcanic eruptions a second (and often third) mode are observed, and consequently a bimodal (or trimodal) lognormal distribution fits the data better (Deshler et al., 1992). For simplicity and because of patchiness of the data, many studies nevertheless use unimodal lognormal distributions (e.g., Kinnison et al., 1994; Russell et al., 1996; Stenchikov et al., 1998; SPARC, 2006). This 
might be legitimate if one of these modes dominates in terms of surface area density and radiative properties.

In this study we compare four methods for retrieval of spectrally resolved optical properties. The first is a method with varying effective radii, distribution widths and number densities (called SAGE_ $4 \lambda$ hereafter) to find the best fit to the four wavelengths of SAGE_ASAP extinction measurements. The second method is that by Stenchikov et al. (1998), called ST98 hereafter (data from G. Stenchikov, personal communications), using the version of the SAGE II data set available at the time (from the V5 series, data from G. Stenchikov, personal communications, 2008) and assuming $\sigma=1.25$. The third is the approach described by Schraner et al. (2008) using SAGE_ASAP and deriving the surface area densities and effective radii based on a principal component analysis using four wavelengths of SAGE II (Thomason et al., 1997b) and assuming a fixed distribution width. Schraner et al. (2008) prescribed the distribution width as $\sigma=1.8$ (named SAGE_1.8 below), which is a mean typical value for the last few decades. However, after volcanic eruptions, $\sigma$ can differ substantially from this value. In this study we repeated the calculation for $\sigma$ equal to 1.2 (SAGE_1.2), which is close to the value for the large particle mode after volcanic eruptions (Deshler et al., 2003) and close to the assumption made by ST98. And finally we carried out calculations with a fourth method using an aerosol model (AER-2D; Weisenstein et al., 1997), where the aerosol size distributions depend directly on microphysical processes and boundary conditions such as $\mathrm{SO}_{2}$ injection mass and location of injection, namely $7 \mathrm{Mt}$ of sulfur injected at $23-25 \mathrm{~km}$ altitude in a simulation called AER_7 hereafter.

The results from SAGE_4 $\lambda$ and AER_7 are used as input for the CCM SOCOL V2 (Schraner et al., 2008) to test the radiative response to these optical forcings. The four different methods used to retrieve size distributions are described subsequently. Methods 1-3 assume unimodal lognormal distributions, while method 4 uses directly the size distributions derived by means of a 2-D aerosol model with 40 size bins.

\subsection{First method: SAGE_4 $\lambda$}

The SAGE_ $4 \lambda$ method computes single lognormal size distributions, which are described by the total number of particles $\left(N_{0}\right)$, the width of the distribution (standard deviation $\sigma$ ) and the mode radius $\left(r_{\mathrm{m}}\right)$ :

$\frac{\mathrm{d} N(r)}{\mathrm{d} r}=N_{0} \frac{\mathrm{e}^{-\frac{1}{2}\left[\frac{\ln ^{2}\left(r / r_{\mathrm{m}}\right)}{\ln ^{2} \sigma}\right]}}{\sqrt{2 \pi} r \ln ^{2} \sigma}$,

where $\mathrm{d} N(r)$ is the number concentration of particles in the interval with radius $\in[r, r+\mathrm{d} r]$. From the size distribution and $\mathrm{H}_{2} \mathrm{SO}_{4}$ wt \% (calculated using year 1991 annual mean ERA-Interim relative humidity), the spectrally resolved optical properties can be calculated by means of Mie theory (Mie, 1908).
In this approach, the four wavelengths $(385,452,525$, and $1024 \mathrm{~nm}$ ) of the SAGE II data are used when available. A similar approach to SAGE_4 $\lambda$ was used by Bingen et al. (2003). In a first step, the mode radius $r_{\mathrm{m}}$, distribution width $\sigma$ and the number density $N_{0}$ are left practically unconstrained for each latitude/altitude point in time $(\sigma \in$ $[1.2,2.6], r_{\mathrm{m}} \in[0.015 \mu \mathrm{m}, 0.5 \mu \mathrm{m}]$, and $N_{0} \in\left[0.5 \mathrm{~cm}^{-3}\right.$, $\left.1000 \mathrm{~cm}^{-3}\right]$ ). For each location and time, the best set of parameters is obtained such that the difference to the SAGE II extinctions at its four wavelengths is minimized. The extinction at each SAGE wavelength is weighted by its standard deviation when available from the SAGE_ASAP data set, giving more weight to more precise measurements. As the four wavelengths of SAGE do not represent entirely independent pieces of information, multiple solutions are possible for the three parameters. Thus, a second step is needed in order to avoid unphysical abrupt changes in the aerosol radii in space and time. Therefore, the effective radius $r_{\text {eff }}$ is calculated out of the previously fitted $r_{\mathrm{m}}$ and $\sigma$ parameters:

$r_{\mathrm{eff}}=r_{\mathrm{m}} e^{\frac{5}{2} \ln ^{2} \sigma}$.

The scatterplot of $r_{\text {eff }}$ as function of the extinction coefficient at $1.024 \mu \mathrm{m}$ is then computed and the median values of the scattered $r_{\text {eff }}$ are taken for each extinction value (see Fig. 1). The calculated median values are then used in the fitting process, and the $\sigma$ and number density are fitted again to minimize the differences to the SAGE observations. The $r_{\text {eff }}$ instead of the mode radius is used for the correlation to the extinction at $1.024 \mu \mathrm{m}$ because it includes information about the distribution width $\sigma$. The correlation of the extinction at $1.024 \mu \mathrm{m}$ with $r_{\text {eff }}$ is hence more robust as it contains more information about the particle size distributions. The SAD is the principle quantity we are interested in. SAD is not used for the correlation because in the second step the number density and the width $\sigma$ are fitted so that the SAGE II extinctions are matched. The fitting of the number density and $\sigma$ thus allows for good agreement to be reached with the extinctions at all SAGE wavelengths. Furthermore, the calculated extinctions show good agreement with ISAMS and HALOE data (extinctions at longer wavelengths; see Sect. 4). The resulting size distribution and SAD are then consistent with observations from SAGE to ISAMS wavelengths. This procedure eliminates the unphysical ambiguities mentioned above.

One exception to this second step was made to describe the tropical lower stratosphere in the first months after the eruption. Indeed in the lower stratosphere the coagulation rate is low due to a small diffusion coefficient of aerosol particles (high pressure, low temperature). Hence, in the volcanic aerosol nucleation plume, the new volcanic aerosols formed after the eruption do not coagulate quickly and the relationship between extinctions and effective radii breaks down. For that reason, until September 1991 the aerosol radius in the tropical lower stratosphere can freely adjust so that available 


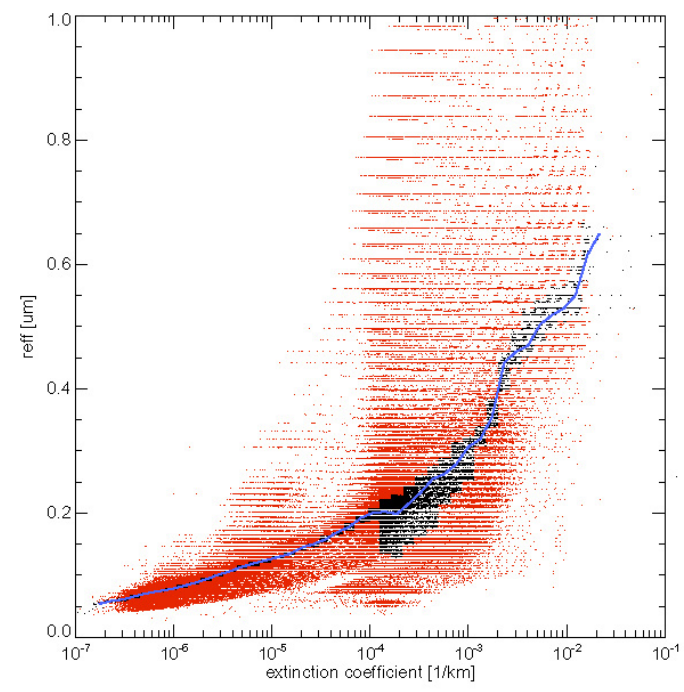

Fig. 1. Effective radii $(\mu \mathrm{m})$ derived from the SAGE_ $4 \lambda$ first step versus extinction coefficients at $1.024 \mu \mathrm{m}$ from SAGE II. Black dots and red dots represent values within and outside one standard deviation, respectively. Blue line represents the median values.

SAGE wavelengths are matched. This leads to smaller (but more numerous) aerosols (see Figs. $3 \mathrm{a}$ and $4 \mathrm{~b}$ and description in Sect. 4 below), and hence reduces the aerosol absorption in this region.

In the gap-filled region, only the extinction at $1.024 \mu \mathrm{m}$ is available and there is not enough information to fit the size distribution parameters. Therefore, $\sigma$ is fixed to 1.2 (close to the value for the large mode after volcanic eruptions). The $r_{\text {eff }}$ is then obtained through its correlation with the extinction, i.e., the same relationship as in the gap-free regions, and finally the number density is fitted to match the $1.024 \mu \mathrm{m}$ extinction.

\subsection{Second method: ST98}

ST98 used effective radii retrieved from CLAES and ISAMS extinction measurements proposed by Grainger et al. (1995) and Lambert et al. (1997). In general there is a good correspondence to effective radii retrieved from SAGE II. They assumed a fixed distribution width of $\sigma=1.25$. In a first step, ST98 calculated the extinction for a number density of one particle per $\mathrm{cm}^{3}$ and in a second step scaled the number density to fit the extinction at $1.024 \mu \mathrm{m}$ with SAGE II measurements. ST98 uses an old SAGE II data set (Russell et al., 1996) with an older satellite retrieval procedure (SAGEv5.9 or similar) and a very simplified gap-filling approach (the last measured SAGE II value in vicinity is taken to fill the gap). ST98 used $\sigma=1.25$ because this distribution width matched best with CLAES optical depth at $2.6 \mu \mathrm{m}$. The optical properties are then calculated with Mie theory assuming $\mathrm{H}_{2} \mathrm{SO}_{4}$ solution droplets of $70 \%$. It should be noted that the retrieval of SAGE v5.9 is significantly different from SAGE V6.0 and higher, and should no longer be used. Conversely, differences in the aerosols from SAGE V6.0 to V7 (recently published) are minor. See Sect. 3 below for details.

\subsection{Third method: SAGE_1.8 and SAGE_1.2}

Based on a principal component analysis using four wavelengths of SAGE II, Thomason et al. (1997b) found the following relationship between the extinctions at $1.024 \mu \mathrm{m}$ and the SAD:

$\mathrm{SAD}=\left\{\begin{array}{ll}425 \times k^{0.68} & \text { for } k<4 \times 10^{-3} \\ 1223 \times k^{0.875} & \text { for } 4 \times 10^{-3}<k<2 \times 10^{-2} \\ 2000 \times k & \text { for } 2 \times 10^{-2}<k\end{array}\right.$,

where $k$ is the extinction coefficient at $1.024 \mu \mathrm{m}$ in $\mathrm{km}^{-1}$ and $\mathrm{SAD}$ is in $\mu \mathrm{m}^{2} \mathrm{~cm}^{-3}$. This relationship is based on the assumption that the wavelength dependence of the extinction is stable for different aerosol extinctions. This assumption is justified for most cases. For SAD around $0.1 \mu \mathrm{m}^{2} \mathrm{~cm}^{-3}$ the uncertainty ranges within $\pm 30 \%$, for SAD greater than $10 \mu \mathrm{m}^{2} \mathrm{~cm}^{-3}$ within $\pm 15 \%$ (Thomason et al., 1997b). However, after the Mt. Pinatubo eruption this relationship differs significantly in the tropical lower stratosphere from the real SAD. This deviation is caused by conjunction of small aerosol size and large extinction in the injection region following the eruption (SPARC, 2006, Chapter 4, pp. 138ff.). Unfortunately there are no aerosol size distribution measurements in the tropics during that time, for example using the OPC (optical particle counter), but it is conceivable that due to changes in the size distribution in post-volcanic times, this relationship can lead to significant errors.

Similarly to the SAD, the effective radius $r_{\text {eff }}$ can be retrieved from the extinction at $1.024 \mu \mathrm{m}$ as follows:

$$
r_{\text {eff }}=\left\{\begin{array}{l}
0.0303 \times[\ln (k)+11.515]+0.16 \\
\text { for } 1 \times 10^{-5}<k<3.0 \times 10^{-4} \\
0.15 \times \exp \left(0.04916 \times[\ln (k)+11.513]^{2}\right) \\
\text { for } 3.0 \times 10^{-4}<k<1.8 \times 10^{-3} \\
0.55 \\
\text { for } 1.8 \times 10^{-3}<k
\end{array} .\right.
$$

Schraner et al. (2008) assumed $\sigma=1.8$ (SAGE_1.8), which is a mean value for the last few decades. However, after volcanic eruptions, $\sigma$ can differ substantially from this value. Following Stenchikov et al. (1998), we repeated the calculation for $\sigma=1.2$ (SAGE_1.2). The extinction is very sensitive to $\sigma$. For the same aerosol mass, if $\sigma$ is large, there are fewer but bigger particles. This affects the radiative properties of the aerosol layer: for the same total mass, smaller particles scatter shortwave radiation more efficiently, but absorb longwave radiation almost to the same degree as larger particles. The number density $N_{0}$ is finally calculated from the SAD, $\sigma$, and $r_{\text {eff. }}$.

The main difference between the SAGE_1.8, SAGE_1.2, SAGE_4 $\lambda$, and ST98 approaches is the estimation of the 
particle size distribution. SAGE_1.8 and SAGE_1.2 follow the approach of SAD conservation from a principal component analysis (Thomason et al., 1997a), whereas SAGE_4 $\lambda$ and ST98 derive size distributions such that the extinctions at the SAGE wavelength(s) match the observations best.

\subsection{Fourth method: AER_7, AER_9, and AER_10_ASAP}

This method uses the aerosol model AER-2D (Weisenstein et al., 1997, 2007). The aerosol size distributions hence depend on the microphysical processes and initial conditions of the AER-2D model. The global domain of the AER-2D model extends from the surface to approximately $60 \mathrm{~km}$ with a vertical resolution of approximately $1.2 \mathrm{~km}$ and horizontal resolution of approximately 9.5 degrees of latitude. The year-by-year temperature and transport fields are taken from Fleming et al. (1999), which were derived from observed ozone, water vapor, zonal wind, temperature, and planetary waves and include the QBO as it affected the zonal-mean circulation in the years 1991-1994. A parameterization of convection (Dvortsov et al., 1998) is employed in the troposphere. The model includes sulfate precursor gases DMS, $\mathrm{CS}_{2}, \mathrm{H}_{2} \mathrm{~S}, \mathrm{OCS}$, and $\mathrm{SO}_{2}$. MSA, $\mathrm{SO}_{2}, \mathrm{SO}_{3}$, and $\mathrm{H}_{2} \mathrm{SO}_{4}$ are product gases. Kinetic and photolytic rates are from Sander et al. (2000). Sulfate particles are created by homogeneous nucleation (Kulmala et al., 2000) near the tropopause and in polar regions and by condensation onto existing particles. The zonal mean temperature is augmented by a temperature distribution that accounts for deviations from the monthly zonal mean temperature in the nucleation calculation. Aerosol composition is a function of temperature and $\mathrm{H}_{2} \mathrm{O}$ concentration according to Tabazadeh et al. (1997). Above about $35 \mathrm{~km}$, particles evaporate to yield $\mathrm{H}_{2} \mathrm{SO}_{4}$ gas, which can photolyze to $\mathrm{SO}_{3}$ and $\mathrm{SO}_{2}$. Particles are resolved into 40 size sections from $0.4 \mathrm{~nm}$ to $3.2 \mu \mathrm{m}$ by volume doubling. Coagulation reduces number densities, while sedimentation reduced the lifetime of larger stratospheric particles. Aerosols are removed below the tropopause by washout and surface deposition.

The main simulation was performed injecting $7 \mathrm{Mt}$ of sulfur at $5^{\circ} \mathrm{S}-14^{\circ} \mathrm{N}$ and $23-25 \mathrm{~km}$ altitude (simulation AER_7). However, measurements for the sulfur amount injected into the stratosphere are subject to uncertainties. Total uncertainty in the amounts range from 7 to up to $13 \mathrm{Mt}$ of sulfur (Lambert et al., 1993; Guo et al., 2004; SPARC, 2006); hence a sensitivity run was performed with AER-2D injecting 9 Mt of sulfur (AER_9). The simulation done for the SPARC ASAP report with $10 \mathrm{Mt}$ of sulfur injected in a broader altitude range $(16-29 \mathrm{~km})$, the absence of tropospheric washout of aerosols above $10 \mathrm{~km}$ (instead of $16 \mathrm{~km}$ ), and climatological wind fields is also shown (AER_10_ASAP).

\section{Differences between pre and post version 6 SAGE II aerosol products}

SAGE II began operation in 1984, when aerosol loading was still enhanced above background levels by the 1982 eruption by El Chichón. The aerosol levels were further enhanced by the eruptions of Nevado del Ruiz in 1985 and Nyamuragira in 1986. Despite these enhancements, the total levels of aerosol opacity along the SAGE II measurement line-ofsight (LOS) geometry remained well below the level at which transmission drops below measurable levels (about an optical depth of 7 along the path between the spacecraft and the Sun) and extinction profiles were made into the upper troposphere throughout this period. After the eruption of Pinatubo in 1991, the LOS optical depth was significantly above 7 and remained so well into 1993, particularly in the tropics. As a result, most profiles were terminated in the lower stratosphere even as high as $25 \mathrm{~km}$ in the first few months after the eruption. Nominally, both the V5 and V6 series of SAGE II products reflect these facts. However, it became apparent to the SAGE II algorithm team that the version 5 series had serious deficiencies that required the algorithm developments that eventually produced V6.0. The most important of the deficiencies was associated with normalization (producing transmission) and altitude registration. SAGE II observes the Sun through the limb of the atmosphere, scanning across the solar disk normal to the surface of the Earth using a mirror, and uses observations made above the atmosphere to convert observations to transmission and eventually profiles of ozone, $\mathrm{NO}_{2}$, water vapor, and aerosol extinction coefficient at four wavelengths. Under most conditions, SAGE II uses observations of the upper and lower edges of the Sun to locate the position of measurements on the Sun and the location of the tangent point in the atmosphere. The location on the Sun is important to converting observations to transmission, while locating events in the atmosphere is crucial for accurate altitude registration of the data. The rate of motion of the scan mirror across the Sun is estimated from the times the edges of the Sun are observed. In cases where optically dense layers are observed, the lower edge of the Sun becomes unobservable and both the Sun position and the position are inferred using only the upper edge of the Sun and a prediction of the rate of motion of the scan mirror. The SAGE II algorithm team observed that the algorithms used prior to V6.0 did a poor job of estimating this scan rate, and as a result the position of points in which the lower of edge of the Sun was obscured had significant errors in both location on the Sun and in the atmosphere. The effect was generally a smearing of the thick parts of the profile to higher altitudes (above where it was actually observed) and below the point at which profiles should have terminated. This was true for clouds as well as the Pinatubo aerosol layer. Versions 6.0 and later employ a substantially improved single Sun-edge algorithm and as such exhibit a far superior performance around optically thick layers. For instance, in V5.93, clouds were frequently 
observed above the tropopause, but in V6.0 and later, with the exception of polar stratospheric clouds, cloud frequency above the tropopause is effectively zero. For Pinatubo, the observed top of the aerosol layer is much sharper and is no longer smeared over multiple kilometers.

As a result, with the release of V6.0 in 2000, the SAGE II algorithm team considered versions prior to V6.0 to be so deficient that these versions were withdrawn from circulation and they strongly recommended that they no longer be employed for any application. Figure 2 demonstrates the differences in these profiles showing a comparison of V5.93 and V6.0 zonally averaged aerosol extinction in the tropics in August 1991. We can see the higher termination of the SAGE II V5.93 extinctions compared to V6.0. The Russell et al. (1996), Sato et al. (1993), and Stenchikov et al. (1998) data sets are built using V5.93 (or similar version) with all its clear defects. However, the data quality issues are exacerbated from this point by the method in which events that terminate above the tropopause (so-called saturated events) are extended to the tropopause. In this data set, the last observation (which is significantly compromised) is extrapolated down to the tropopause and not otherwise constrained by any observation. The ASAP data set is a significant improvement over that available in 1998. Foremost, it is based on V6.2, a far superior version than anything prior to V6.0, and it also uses a collection of corroborative data, primarily ground- and aircraft-based lidar observations, to fill the observations lost to the extreme opacity of the stratosphere in 1991 through 1993 (SPARC, 2006). While these observations are converted to $1020 \mathrm{~nm}$ extinction using an uncertain extinction-to-backscatter ratio, converting to bulk properties (e.g., SAD) is based on statistical relationships inferred from the SAGE II multichannel data and corroborative data in the tropics is scarce, and there can be no doubt that this approach is many times more robust than that used in the earlier data set.

The ST98 extinctions are based on similar early versions of the SAGE data as the $5 \mathrm{~km}$ resolution optical depths values provided by Sato et al. (1993), both having to fill the gap between the point of termination at high altitude towards the tropopause by some extrapolation, and thus showing large differences compared to the state-of-the-art SAGE ASAP data (Fig. 2), which peaks around $22 \mathrm{~km}$. Also, SAGE V5.93 data show larger values than ST98 above the termination altitude, which might be due to differences in altitude resolution.

\section{Results}

The extinction, single-scattering albedo. and asymmetry factor at wavelengths covering the whole spectral range are the key parameters to model the radiative impact of stratospheric aerosols. These quantities are calculated by means of Mie theory (Mie, 1908) for spherical dielectric aerosol

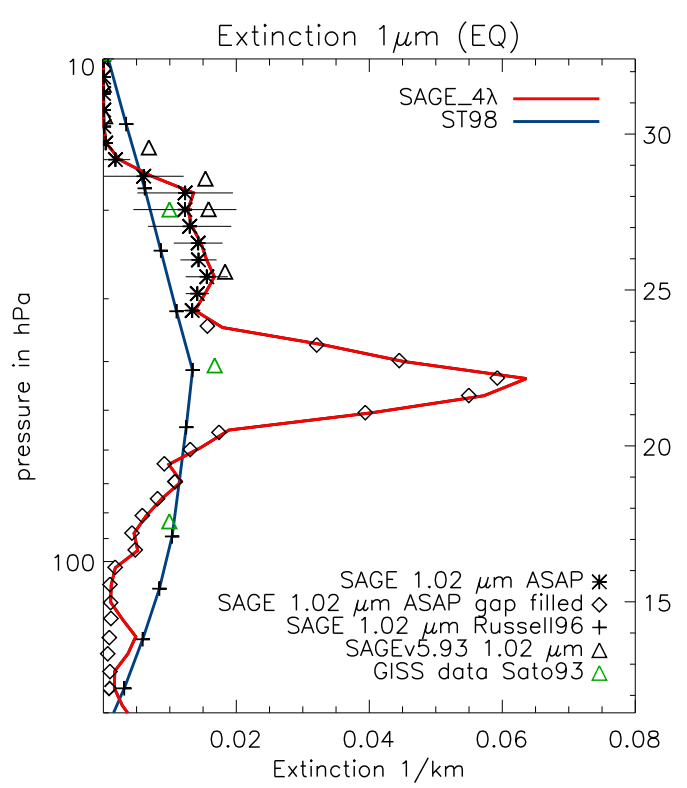

Fig. 2. Zonal mean extinction for August 1991 at $1.024 \mu \mathrm{m}$ at the Equator. Horizontal lines in symbols show standard deviations of SAGE_ASAP measurements.

particles using indices measured by Luo et al. (1996) and Biermann et al. (2000) that cover the temperature range from 185 to $300 \mathrm{~K}$ and composition range for $\mathrm{H}_{2} \mathrm{SO}_{4}$ from 0 to $80 \mathrm{wt} \%$. Luo et al. (1996) report values for refractive index for $0.35<\lambda<2 \mu \mathrm{m}$, whereas Biermann et al. (2000) report values for the complex refractive index for $2 \mu \mathrm{m}<\lambda<20 \mu \mathrm{m}$.

Temperature and $\mathrm{H}_{2} \mathrm{SO}_{4}$ weight fractions (calculated based on year 1991 annual mean ERA-Interim relative humidities) are applied to the retrieved size distributions.

\subsection{Size distributions}

Figure 3 shows size distributions derived from SAGE_4 $\lambda$ and from the AER-2D model runs for a $7 \mathrm{Mt}$ eruption (AER_7) and volcanically quiescent conditions (Background). Furthermore, it shows a comparison with OPC measurements from Laramie, Wyoming (Rosen, 1964; Deshler et al., 1992). The AER-derived size distributions at the Equator in $\mathrm{Au}-$ gust 1991 (Fig. 3a) show the development of the volcanic mode and a shift of the background mode to larger radii. The SAGE_4 $\lambda$ background size distribution (taken from January 1991) shows less small aerosols compared to the AER background simulation. In August 1991 at $64 \mathrm{hPa}$, the SAGE_4 $\lambda$ approach including the modification in the early volcanic plume (as discussed in the Sect. 2) shows a wide unimodal distribution with a large number of small aerosols, while this is not the case for the SAGE_4 $\lambda$ distribution not incorporating this special modification. The modification allows for the SAGE_ $4 \lambda$ method to capture the high $0.525 \mu \mathrm{m}$ to $1.024 \mu \mathrm{m}$ extinction ratio below $60 \mathrm{hPa}$ right after the 

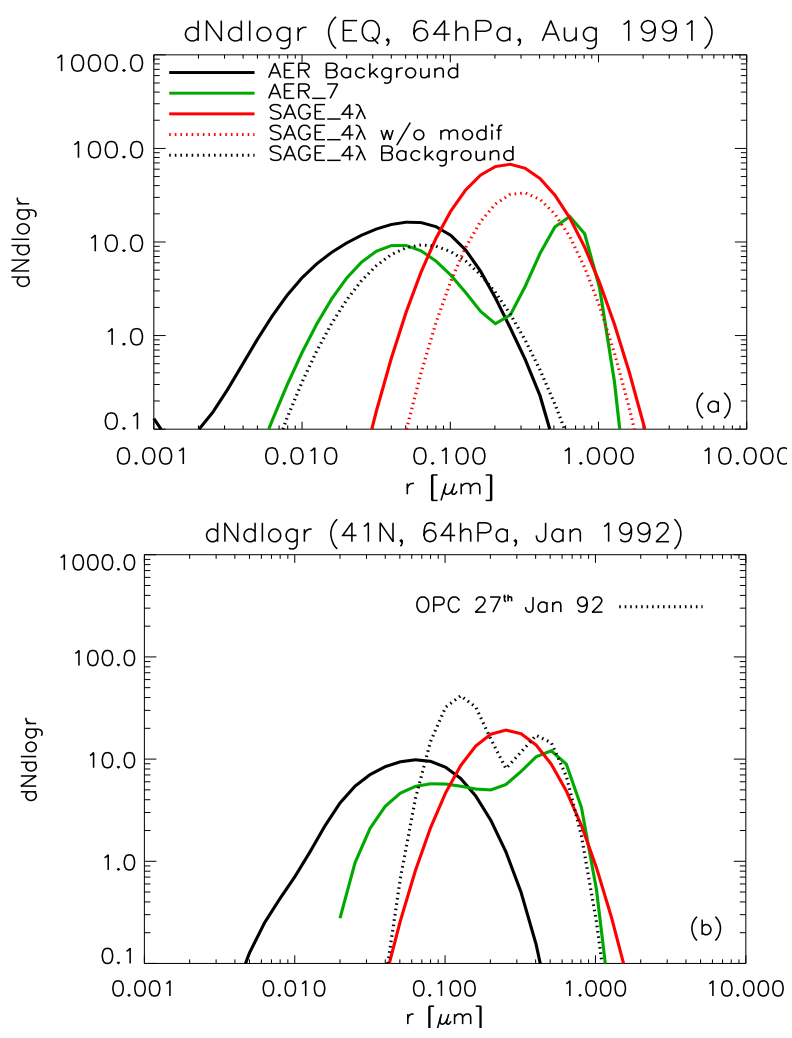

Fig. 3. Differential number density $\mathrm{d} N / \mathrm{d} \log r$ as a function of aerosol radius at $64 \mathrm{hPa}$ for (a) the Equator $\left(5^{\circ} \mathrm{S}-5^{\circ} \mathrm{N}\right)$ in August 1991, and (b) northern midlatitudes $\left(40^{\circ} \mathrm{N}\right)$ in January 1992. SAGE_4 $\lambda$ background size distribution is represented by the January 1991 background conditions. Dashed black line in (b) shows the OPC measurements at Laramie, Wyoming $\left(41^{\circ} \mathrm{N}\right)$.

eruption (Fig. 4b). This high ratio is the result of high particle number densities as a consequence of slow coagulation due to a limited diffusion coefficient of aerosol particles (high pressure, low temperature). Figure $3 \mathrm{~b}$ shows a comparison with $\mathrm{OPC}$ measurements from Laramie $\left(41^{\circ} \mathrm{N}\right)$ at $64 \mathrm{hPa}$ for January 1992. The SAGE_ $4 \lambda$ approach covers the two modes of the observed distribution but exhibits fewer aerosols below $0.35 \mu \mathrm{m}$. This deficiency does not significantly affect the later retrievals of longwave extinction and heating rates, because the SAGE_ $4 \lambda$ result provides a good approximation for the large particles and hence for aerosol volume density. The AER_7 simulation captures well the high end of the distribution but underestimates the radius of the aerosols in the background mode, possibly due to a too rapid latitudinal distribution in the 2-D model.

From these size distributions, extinctions are computed for short and long wavelengths and compared to measurements from SAGE II at $0.525 \mu \mathrm{m}$ and $1.024 \mu \mathrm{m}$, HALOE at $3.46 \mu \mathrm{m}$ and $5.26 \mu \mathrm{m}$, and ISAMS at $12.1 \mu \mathrm{m}$.
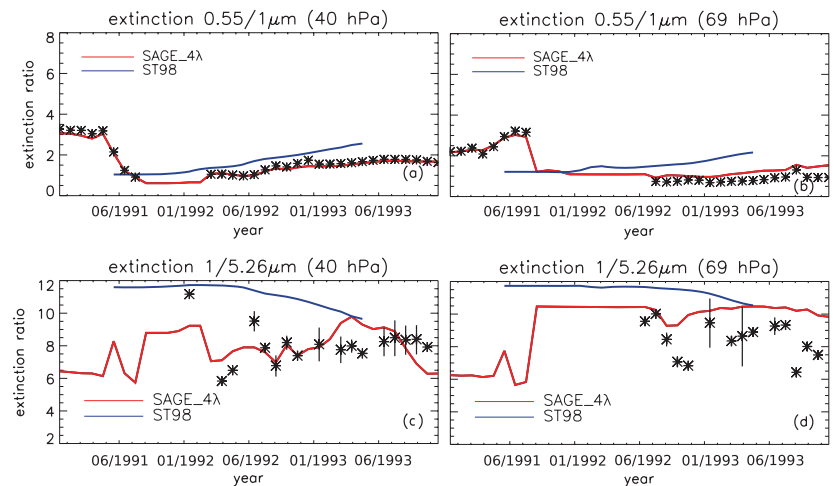

Fig. 4. Extinction ratio of $0.525 \mu \mathrm{m} / 1.024 \mu \mathrm{m} \quad(\mathbf{a}, \quad$ b) and $1 \mu \mathrm{m} / 5.26 \mu \mathrm{m}$ (c, d). At the Equator at $40 \mathrm{hPa}$ altitude (a, c) and at $69 \mathrm{hPa}$ altitude $(\mathbf{b}, \mathbf{d})$. Asterisks in $(\mathbf{a}, \mathbf{b})$ show ratio of SAGE II $0.525 \mu \mathrm{m} / 1.024 \mu \mathrm{m}$ (SPARC, 2006) and asterisks in (c, d) show ratio of SAGE II $1.024 \mu \mathrm{m}$ and HALOE $5.26 \mu \mathrm{m}$.

\subsection{Shortwave extinctions}

In the visible wavelengths, the SAGE_41 approach shows, by construction, extinction coefficients close to the SAGE II data (Fig. 5). Conversely, the ST98 approach shows extinction values close to observations in the $20-50 \mathrm{hPa}$ pressure region but overestimates extinctions above and below. The AER simulations show too large values at the Equator (Fig. 5a) but AER_7 and even AER_9 are underestimating extinction coefficients in the extratropics (Fig. 5b). The SAGE_1.8 and SAGE_1.2 approaches show very similar values and show generally too high extinctions.

SAGE_4 $\lambda$ shows perfect agreement with SAGE_ASAP at $1.024 \mu \mathrm{m}$ as shown in Figs. 6a and $7 \mathrm{a}$ at the Equator. This illustrates the accuracy of SAGE_4 $\lambda$ in matching the various wavelengths of SAGE_ASAP by adjusting the number density and distribution width of the aerosols. ST98 with retrieval based on old data (Russell et al., 1996) is less than half that of SAGE_ASAP $1.024 \mu \mathrm{m}$ measurements at $40 \mathrm{hPa}$ in 1991 (Fig. 6a). Above $20 \mathrm{hPa}$ and below $60 \mathrm{hPa}$ at the Equator, ST98 overestimates SAGE_ASAP data (Fig. 7a). Accordingly, heating rate calculations in GCMs and CCMs based on ST98 use a data set that significantly underestimates the extinction at $1.024 \mu \mathrm{m}$ in the tropical stratosphere in the $50-30 \mathrm{hPa}$ range and overestimates it below.

The AER simulations significantly overestimate the extinction at the Equator when compared to SAGE_ASAP. However, in the extratropics, AER_7 results are generally in very good agreement with the observations (Fig. 8a, b). At these latitudes, SAGE_4 $\lambda$ and ST98 show similar values, in agreement with SAGE_ASAP data.

The profiles of Fig. 7a show that SAGE_1.8 and especially SAGE_1.2 overestimate the extinctions at $1.024 \mu \mathrm{m}$ at all altitudes. 

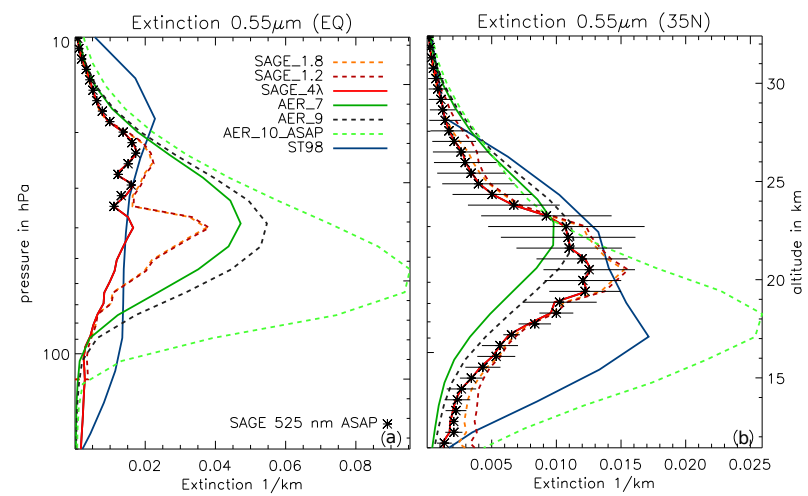

Fig. 5. Zonal mean extinction for December 1991 at $0.525 \mu \mathrm{m}$ at $5^{\circ} \mathrm{S}-5^{\circ} \mathrm{N}$ (a) and $30-40^{\circ} \mathrm{N}$ (b). Horizontal lines in symbols show standard deviations of SAGE_ASAP measurements.

\subsection{Longwave extinctions}

All the SAGE-derived methods are based on extinctions at short wavelengths $(\lambda \leq 1.024 \mu \mathrm{m})$. The longwave radiation peaks are mainly responsible for the in situ heating. Whether the retrieved aerosol size distribution can represent the extinctions at these long wavelengths is a critical question. In the following section, we compare the calculated results with satellite measurements at infrared wavelengths.

The extinctions at $3.46 \mu \mathrm{m}, 5.26 \mu \mathrm{m}$, and $12.1 \mu \mathrm{m}$ provide information on the aerosol absorption in the terrestrial IR that is mostly responsible for the stratospheric warming after an eruption. At $40 \mathrm{hPa}$ (Fig. 6b) SAGE_4 $\lambda$ is in good agreement with available measurements at the Equator, while ST98 exhibits too low values and AER_7 overestimates the extinction until spring 1992. However, at midlatitudes, results from AER_7 at $12.1 \mu \mathrm{m}$ agree better with observations, while ST98 underestimates the extinctions at $12.1 \mu \mathrm{m}$ compared to ISAMS observations (Fig. 8c, d) despite showing accurate extinctions at $1.024 \mu \mathrm{m}$ (Fig. 8a, b). This indicates a too high $1.024 \mu \mathrm{m}$ to $12.1 \mu \mathrm{m}$ extinction ratio in ST98. In December 1991 at $40 \mathrm{hPa}$, large extinctions are displayed in SAGE_1.8 and SAGE_1.2 that are significantly larger than the ISAMS values (Fig. 7c). Conversely, at $30 \mathrm{hPa}$, SAGE_1.8, SAGE_1.2, and SAGE_4 $\lambda$ slightly underestimate the extinctions.

The SAGE_ $4 \lambda$ calculation shows a reasonable agreement with the data, especially in the level of high extinction above $40 \mathrm{hPa}$, while ST98 results again are less than half the measurements, approaching the observations only below $70 \mathrm{hPa}$. The low extinctions at $12.1 \mu \mathrm{m}$ from the ST98 arise both from its use of an outdated version of the SAGE retrieval algorithm and gap filling and from a too high $1.024 \mu \mathrm{m}$ to IR extinction ratio compared with observation (see Fig. $4 \mathrm{c}$, d).

Compared to HALOE data, SAGE_ $4 \lambda$ also show good agreement after the eruption, with differences to the HALOE extinctions at $3.46 \mu \mathrm{m}$ mostly below $25 \%$ right after the

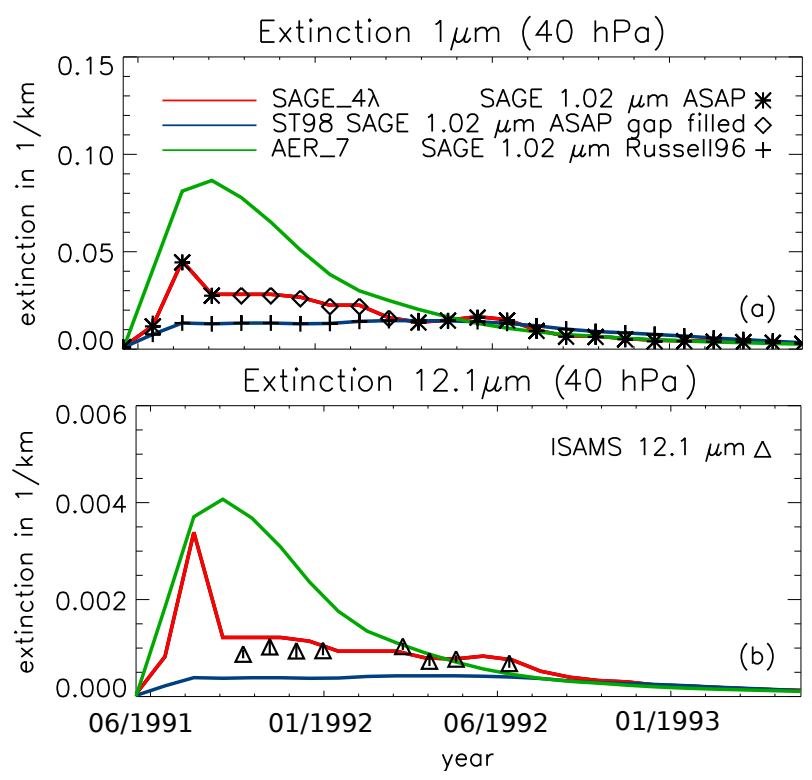

Fig. 6. Zonal mean $40 \mathrm{hPa}$ extinction from June 1991 to June 1993 for $1.024 \mu \mathrm{m}$ (a) and $12.1 \mu \mathrm{m}$ (b) at $5^{\circ} \mathrm{S}-5^{\circ} \mathrm{N}$. Vertical lines show in symbols standard deviations of SAGE ASAP measurements and the random error estimation + standard deviation for the ISAMS measurements.

eruption at the Equator and midlatitudes (Fig. 9). The 30 $40^{\circ} \mathrm{N}$ extinctions at $5.26 \mu \mathrm{m}$ six months after the eruption are also comparable to HALOE observation for SAGE_4 $\lambda$ despite an overestimation around $40 \mathrm{hPa}$ (Fig. 10b). This overestimation at $40 \mathrm{hPa}$ is also seen when compared to ISAMS measurements (Fig. 7c). SAGE_1.2 and especially SAGE_1.8 show mostly too large extinctions. The ST98 extinctions at $5.26 \mu \mathrm{m}$ show a similar too low altitudinal distribution compared to observations as its $12.1 \mu \mathrm{m}$ wavelength did. HALOE values are larger than ST98 between $70 \mathrm{hPa}$ and $40 \mathrm{hPa}$ (twice larger at $60 \mathrm{hPa}$ ), and much lower below.

The measurements at the far-infrared range (HALOE and ISAMS) were not used in the retrieval procedure of the SAGE_ $4 \lambda$ size distributions. The good agreement between ISAMS/HALOE and SAGE_ $4 \lambda$ suggests the following:

1. The assumed unimodal lognormal size distribution is capable of describing both extinction coefficients in the short wavelength range but also in the long wavelength range, as it captures the optically relevant features of the actual size distribution.

2. The derived lognormal size distributions based on data only at SAGE wavelengths are reasonable and allow for us to calculate radiative properties also in the far infrared.

The sensitivity simulations performed with the AER model show the influence of the injection mass on the extinction values. Clearly, the AER_9 and AER_10_ASAP simulations 


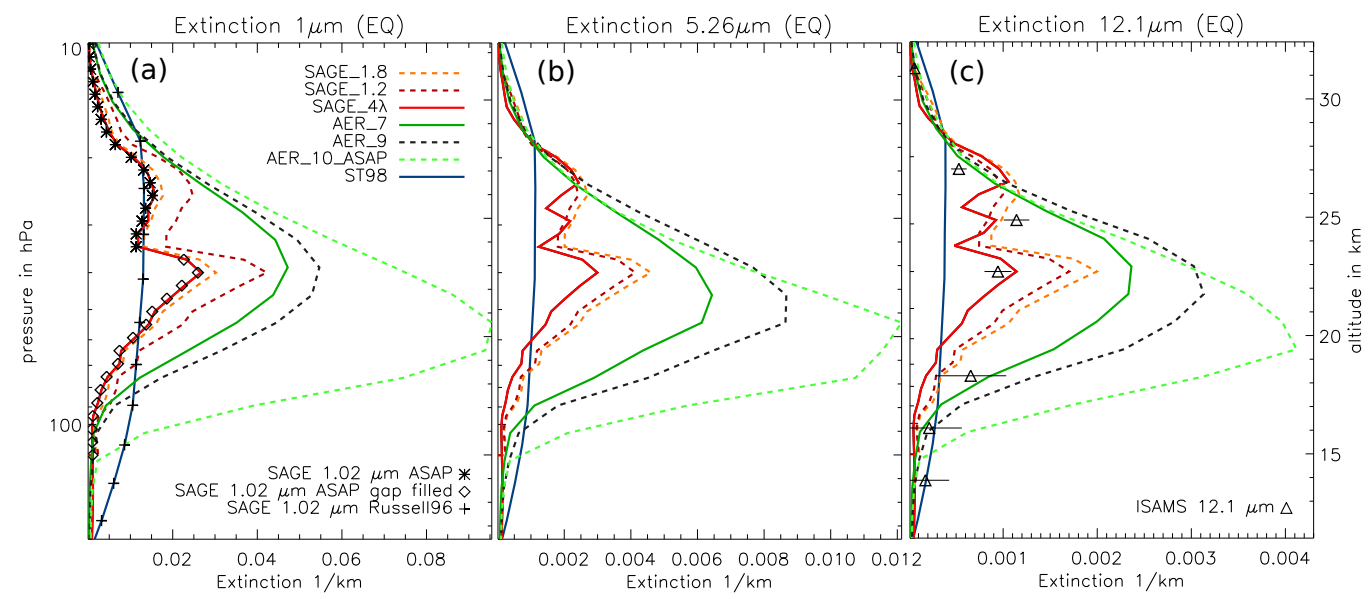

Fig. 7. Zonal mean extinction for December 1991 at $1.024 \mu \mathrm{m}, 5.26 \mu \mathrm{m}$, and $12.1 \mu \mathrm{m}$ at $5^{\circ} \mathrm{S}-5^{\circ} \mathrm{N}$. Horizontal lines in symbols show standard deviations of SAGE ASAP measurements and the random error estimation + standard deviation for the ISAMS measurements. No HALOE measurements are available at $5.26 \mu \mathrm{m}$.
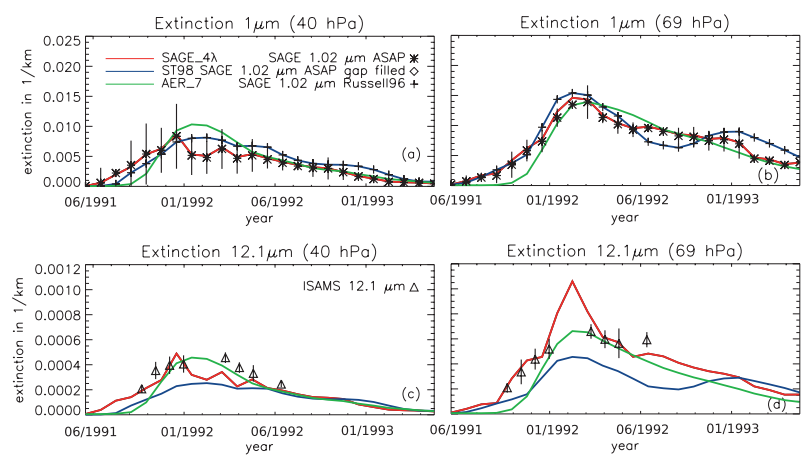

Fig. 8. Zonal mean extinction from June 1991 to June 1993 for $1.024 \mu \mathrm{m}$ and $12.1 \mu \mathrm{m}$ at $30-40^{\circ} \mathrm{N}$. Left column at $40 \mathrm{hPa}$; right column at $69 \mathrm{hPa}$. Vertical lines in symbols show standard deviations of SAGE ASAP measurements and the random error estimation + standard deviation for the ISAMS measurements.

yield too high extinctions. The $7 \mathrm{Mt}$ simulation (AER_7) performs the best but still overestimates extinctions at the Equator. Figure $7 \mathrm{a}$ and $\mathrm{c}$ shows that six months after the eruption, AER simulations generally show too large values for extinctions at $1.024 \mu \mathrm{m}$ and $12.6 \mu \mathrm{m}$ at the Equator. Below $70 \mathrm{hPa}$, the extinction profiles at $12.6 \mu \mathrm{m}$ of AER_7 and AER_9 are largely consistent with observations, while AER_10_ASAP shows a significant extinction overestimation at low altitudes due mainly to the absence of washout above $10 \mathrm{~km}$ in this simulation. At midlatitudes, AER_7 and AER_9 values are close to observations, with AER_10_ASAP still being an outlier (Fig. 10c). At $5.26 \mu \mathrm{m}$, the AER simulation AER_10_ASAP is again an outlier compared to HALOE data, while AER_9 extinctions are reasonable but showing a too broad altitude distribution (Fig. 10b).

\subsection{Stratospheric temperatures}

Simulations with the CCM SOCOL V2 (Schraner et al., 2008) were carried out to test the stratospheric response to the SAGE_4 $\lambda$, SAGE_1.2, SAGE_1.8, and AER_7 scenarios. The GCM part of SOCOL is based on ECHAM-4 using the ECHAM-4 radiation code. For the radiative transfer calculations spectral extinctions, single-scattering albedos, and asymmetry factors (as well as the surface area densities for heterogeneous chemistry calculations) directly derived from the described methods were provided as spaceand time-dependent forcings to SOCOL. SOCOL V2 is a spectral model with T30 horizontal truncation and 39 vertical levels. Simulations carried here include a nudging of the QBO (from ERA-40 data) and prescribed SSTs (Sea Surface Temperatures), QBO (Quasi Biennial Oscillation) (Rayner, 2003). The model spectral bands consist of two shortwave and six longwave wavebands.

In Fig. 11, these SOCOL results are compared to the ERA40 reanalysis and to values from different GCMs as shown in Lanzante and Free (2007) and from CCMs as shown in Eyring et al. (2006) and SPARC-CCMVal (2010). The stratospheric warming after the eruption is in general overestimated. SAGE_ $4 \lambda$ shows a bias between $1 \mathrm{~K}$ in fall 1991 and $3 \mathrm{~K}$ in spring 1992 in the tropics at $50 \mathrm{hPa}$ compared to ERAInterim data (Fig. 11a). Compared to GCM studies using the Sato et al. (1993) or Ammann et al. (2003) data sets (Lanzante and Free, 2007), the SAGE_4 $\lambda$ is in the high range of the tropical warming overestimation, while AER_7 exhibits even larger values. In the same way, the global average temperature increase at $50 \mathrm{hPa}$ from the SAGE_ $4 \lambda$ experiment is too high by $1.5 \mathrm{~K}$ in spring 1992 (Fig. 11b).

The temperature overestimation after the Pinatubo eruption using the AER approach has already been pointed 

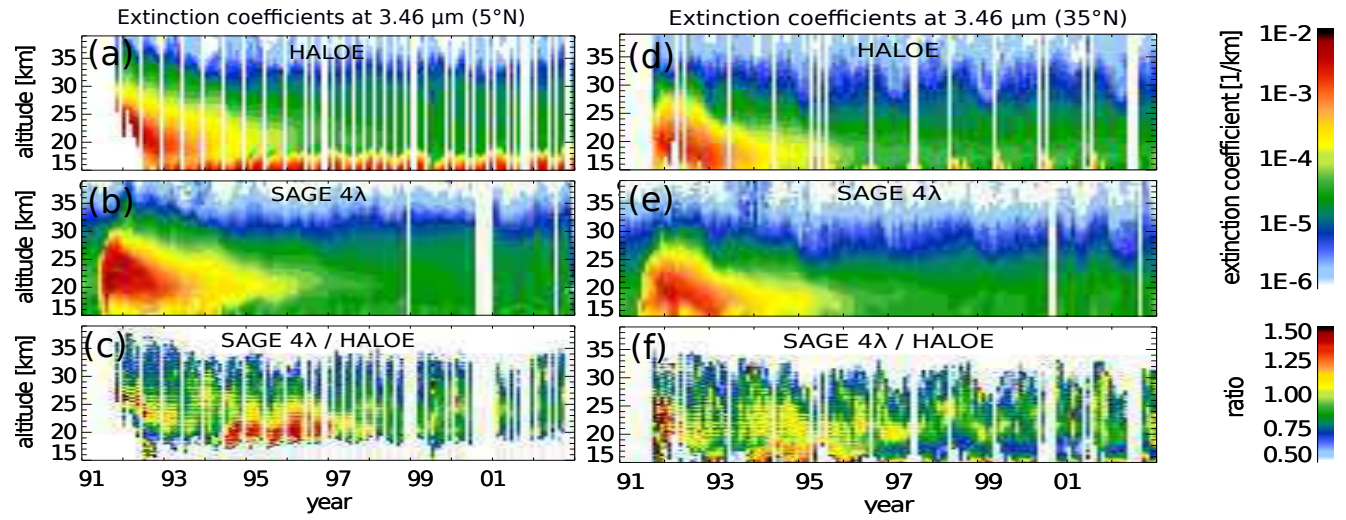

Fig. 9. HALOE $5^{\circ} \mathrm{N}$ extinction coefficients at $3.46 \mu \mathrm{m}$ (a). Calculated $5^{\circ} \mathrm{N}$ extinction coefficients at $3.46 \mu \mathrm{m}$ using the SAGE_4 $\lambda$ size distribution (b). Ratio of the SAGE_4 $4 \lambda$ extinction coefficients to HALOE measurements (c). HALOE $35^{\circ} \mathrm{N}$ extinction coefficients at $3.46 \mu \mathrm{m}$ (d). Calculated $35^{\circ} \mathrm{N}$ extinction coefficients at $3.46 \mu \mathrm{m}$ using the SAGE_4 $\lambda$ size distribution (e). Ratio of the SAGE_4 $\lambda$ extinction coefficients to HALOE measurements (f).

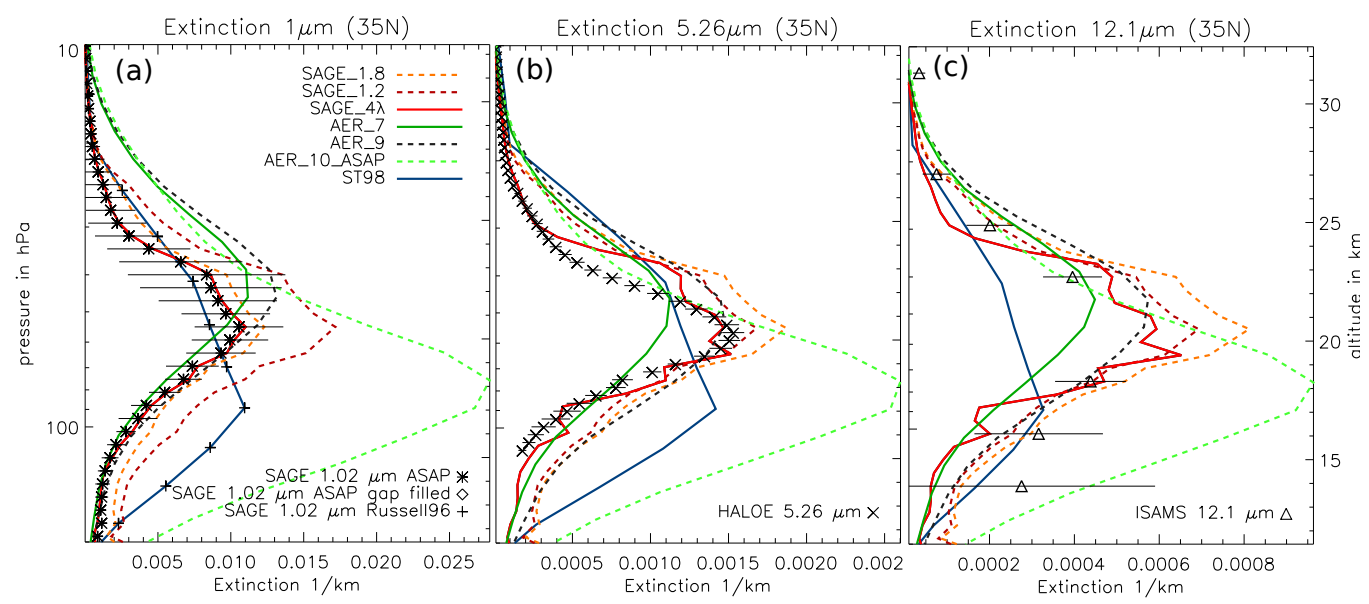

Fig. 10. Zonal mean extinction for December 1991 at $1.024 \mu \mathrm{m}, 5.26 \mu \mathrm{m}$, and $12.1 \mu \mathrm{m}$ at $30-40^{\circ} \mathrm{N}$. Horizontal lines in symbols show standard deviations of SAGE ASAP measurements, standard deviations of HALOE measurements, and the random error estimation + standard deviation for the ISAMS measurements.

out by Heckendorn et al. (2009) and similar results are found in our study (e.g., their Fig. 2a is practically identical to our Fig. 11a). The AER results are higher than the SAGE_4 $\lambda$ calculations for the end of 1991. The global average temperature increase at $70 \mathrm{hPa}$ shows similar characteristics (Fig. 11d). Compared to CCM studies using heating rates from Stenchikov et al. (1998) or derived from SPARC (2006) surface area density data or Sato et al. (1993) extinction, SOCOL forced by SAGE_ $4 \lambda$ lies in the high range of their estimations at $50 \mathrm{hPa}$ and $70 \mathrm{hPa}$. In the tropical tropopause region $(100 \mathrm{hPa}), \mathrm{SAGE} \_4 \lambda$ diverges from ERAInterim anomalies in late 1991 (Fig. 11c). At $100 \mathrm{hPa}$, the SAGE_ $4 \lambda$ approach leads to a clear improvement compared to the GCM studies, while AER_7 is inside the range of their results. The SAGE_1.8 and SAGE_1.2 scenarios lead to im- portant overestimations of the stratospheric heating, similar to the AER_7 results with even significantly larger values at $50 \mathrm{hPa}$ after mid-1992. Temperatures in SAGE_1.2 are close to the SAGE_1.8 results, showing the balance between the near-infrared and infrared influences as the use of a narrower distribution width led to larger extinctions in the near infrared and smaller extinctions at longer wavelengths (Fig. 7). Note that while the volcanic influence is dominating the temperature responses in the simulations, other causes not directly related to heating by volcanic aerosols may explain part of the signals as seen in the differences between simulations before the eruption. While we show here the influence of the volcanic aerosol forcing used on stratospheric temperature, the model vertical resolution, QBO representation, and biases (e.g., in the representation of climatological 

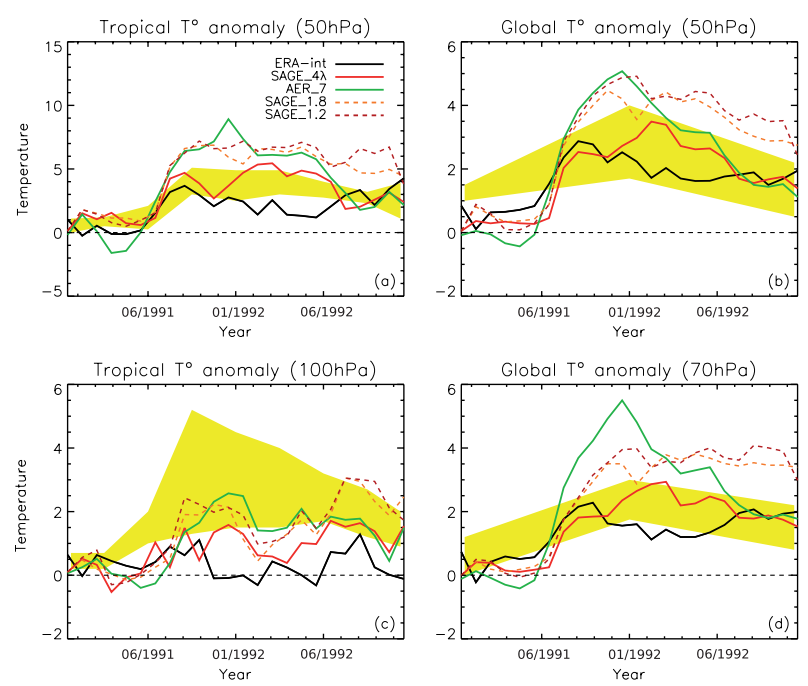

Fig. 11. Zonal mean temperature anomalies from SOCOL for tropics $\left(20^{\circ} \mathrm{S}-20^{\circ} \mathrm{N}\right)$ at $50 \mathrm{hPa}($ a) and $100 \mathrm{hPa}(\mathbf{c})$ as well as global mean anomaly at $50 \mathrm{hPa}(\mathbf{b})$ and $70 \mathrm{hPa}(\mathbf{d})$. Scenarios' anomalies (SAGE_4 $\lambda$, SAGE_1.8,SAGE_1.2 and AER_7) are computed with respect to a control simulation. Black line represents ERA-Interim temperature anomalies with respect to 1995-1999. Shadings display approximate anomaly ranges calculated by GCMs as examined in Lanzante and Free (2007) for (a, c) and by CCMs as examined in Eyring et al. (2006) in (b) and SPARC-CCMVal (2010) in (d).

stratospheric temperatures) are important factors that should be assessed in each model in order to explain the overheating after the Pinatubo eruption.

\section{Conclusions}

The volcanic eruption of Mt. Pinatubo in June 1991 is the best documented large eruption on record; however, lack of measurements in the tropics in the first months after the eruption due to optical saturation limits the quality of the data. GCMs and CCMs show important variations in lower stratospheric temperatures following the Pinatubo eruption with a tendency to overestimate the warming (SPARC-CCMVal, 2010; Gettelman et al., 2010; Lanzante and Free, 2007). CCMs that implement the aerosol heating using the precalculated heating rates of Stenchikov et al. (1998) overestimate the stratospheric warming only slightly, but this result should be regarded with caution as the ST98 data set presents too low IR extinctions compared to measurements. This underestimation of the infrared extinctions is due to the use of a version of the SAGE retrieval algorithm and gap filling that was available at that time (1998) but that is now outdated. The IR extinctions underestimation in ST98 may be also partly due to the method used (e.g., fixed distribution width) as spectral extinction variations are biased towards too high $1 \mu \mathrm{m}$ to IR ratio). GCMs that in the past have used the Sato et al. (1993)
GISS data set (also based on an outdated version of SAGE II) and a fixed distribution width, tend to overestimate the warming, as do CCMs using heating rates derived from SPARC (2006) SAD data (Morgenstern et al., 2010; Lanzante and Free, 2007). The results from these approaches will depend on the choice of the aerosol distribution width. Using a fixed width of either 1.8 or 1.2 together with SPARC (2006) SAD and effective radii did not lead to satisfactory IR extinctions in our study, whereas the SAGE_ $4 \lambda$ method overcomes this problem. Therefore, extinctions or heating rates derived from the Stenchikov et al. (1998) or Sato et al. (1993) data sets should no longer be used in studies covering the SAGE II period.

We investigated in this study the influence of the improvement of the general satellite extinction processing algorithm and of the gap filling (SPARC, 2006) on the stratospheric warming after the Pinatubo eruption. Using the state-of-theart SAGE II retrieval algorithm, we derived aerosol size distributions with different methods to calculate spectrally resolved optical properties for the Pinatubo eruption and tested the accuracy of the infrared extinctions compared to HALOE and ISAMS measurements. The established data set uses a fit to the four wavelengths of SAGE II (SAGE_4 $\lambda$ ) and shows a good agreement with extinction profiles and evolutions of both SAGE II visible/near-infrared wavelengths and IR measurements from HALOE at $3.46 \mu \mathrm{m}$ and 5.26 $\mu \mathrm{m}$ and ISAMS at $12.1 \mu \mathrm{m}$, while the data set from Stenchikov et al. (1998) displays too low extinctions above $20 \mathrm{~km}$. The use of SPARC (2006) SAD data and a fixed distribution width (SAGE_1.8, SAGE_1.2) to infer the optical parameters leads to somewhat too large extinctions in the infrared compared to measurements. Results using the microphysical aerosol model AER to generate the aerosol size distributions reveal a clear overestimation of the extinctions at the Equator (even though the AER model was found to be one of the most successful aerosol models in SPARC, 2006) but a good agreement in the extratropics.

Using the SAGE_4 $\lambda$ data to simulate the Pinatubo eruption in the CCM SOCOL leads to a significant overestimation of the tropical stratospheric temperatures, by up to $3 \mathrm{~K}$ at $50 \mathrm{hPa}$, but a generally good agreement at $100 \mathrm{hPa}$.

For GCM and CCM simulations using volcanic forcings with longwave extinctions for the Pinatubo eruption lower than found in this study for the aerosol peak around 40$50 \mathrm{hPa}$, we argue that the stratospheric temperature increase overestimation often present in these models is unlikely due to an error in the volcanic aerosol forcing data, and could even be amplified by using a data set closer to the SAGE_ASAP, HALOE, and ISAMS observations. Rather, the cause of this problem must be sought in the use of outdated data sets, in how the data are implemented in the models, or in model artifacts (e.g., in the radiative or dynamical codes). Conversely, the warming at the tropical tropopause could be reduced by using the new SAGE_ASAP data and an appropriate size distribution retrieval. The tropical 
tropopause is a critical region as too high heating rates in this region after the eruption can lead to an overestimation of the water vapor flux across the tropopause (Joshi and Shine, 2003) with a crucial impact on stratospheric humidity and stratospheric chemistry in general.

Finally, our study shows that the use of the surface area density and effective radius information from a principal component analysis (as done in SPARC, 2006) combined with a fixed distribution width of either 1.8 or 1.2 leads to an overestimation of the infrared extinctions and therefore should also be avoided.

Note added in proof: In the meantime, SAGE V7.0 has appeared; however with respect to aerosol extinctions, there are only marginal differences compared to V6.2 used in this paper.

Acknowledgements. The origin of this work dates back to the SPARC Assessment of Stratospheric Aerosol Properties (ASAP). We would like to acknowledge funding from the Cogito foundation and from the Department of Environmental Science of ETH Zurich. Discussions with S. Fueglistaler in the early phase of this work are gratefully acknowledged.

\section{References}

Ammann, C. M., Meehl, G. A., Washington, W. M., and Zender, C. S.: A monthly and latitudinally varying volcanic forcing dataset in simulations of 20th century climate, Geophys. Res. Lett., 30, 1657, doi:10.1029/2003GL016875, 2003.

Antuña, J. C., Robock, A., Stenchikov, G. L., Thomason, L. W., and Barnes, J. E.: Lidar validation of SAGE II aerosol measurements after the 1991 Mount Pinatubo eruption, J. Geophys. Res. Atmos., 107, 4194, doi:10.1029/2001JD001441, 2002.

Antuña, J. C., Robock, A., Stenchikov, G., Zhou, J., David, C., Barnes, J., and Thomason, L.: Spatial and temporal variability of the stratospheric aerosol cloud produced by the 1991 Mount Pinatubo eruption, J. Geophys. Res. Atmos., 108, 4624, doi:10.1029/2003JD003722, 2003.

Biermann, U. M., Luo, B. P., and Peter, T.: Absorption spectra and optical constants of binary and ternary solutions of $\mathrm{H}_{2} \mathrm{SO}_{4}$, $\mathrm{HNO}_{3}$, and $\mathrm{H}_{2} \mathrm{O}$ in the mid infrared at atmospheric temperatures, J. Phys. Chem. A, 104, 783-793, 2000.

Bingen, C., Vanhellemont, F., and Fussen, D.: A new regularized inversion method for the retrieval of stratospheric aerosol size distributions applied to 16 years of SAGE II data (1984-2000): method, results and validation, Ann. Geophys., 21, 797-804, doi:10.5194/angeo-21-797-2003, 2003.

Bluth, G. J. S., Doiron, S. D., Schnetzler, C. C., Krueger, A. J., and Walter, L. S.: Global tracking of the $\mathrm{SO}_{2}$ clouds from the June, 1991 Mount-Pinatubo eruptions, Geophys. Res. Lett., 19, 151$154,1992$.

Deshler, T., Hoffman, D. J., Johnson, B. J., and Rozier, W.: Balloonborne measurements of the Pinatubo aerosol size-distribution and volatitily at Laramie, Wyoming, during summer of 1991, Geophys. Res. Lett., 19, 199-202, 1992.

Deshler, T., Hervig, M. E., Hofmann, D. J., Rosen, J. M., and Liley, J. B.: Thirty years of in situ stratospheric aerosol size distribution measurements from Laramie, Wyoming (41 N), using balloon-borne instruments, J. Geophys. Res., 108, 4167, doi:10.1029/2002JD002514, 2003.

Dvortsov, V. L., Geller, M. A., and Yudin, V. A.: Parameterization of the convective transport in a two-dimensional chemistrytransport model and its validation with radon 222 and other tracer simulations, J. Geophys. Res., 103, 22047-22062, 1998.

Eyring, V., Butchart, N., Waugh, D. W., Akiyoshi, H., Austin, J., Bekki, S., Bodeker, G. E., Boville, B. A., Brühl, C., Chipperfield, M. P., Cordero, E., Dameris, M., Deushi, M., Fioletov, V. E., Frith, S. M., Garcia, R. R., Gettelman, A., Giorgetta, M. A., Grewe, V., Jourdain, L., Kinnison, E., Mancini, E., Manzini, E., Marchand, M., Marsh, D. R., Nagashima, T., Newman, P. A., Nielsen, J. E., Pawson, S., Pitari, G., Plummer, D. A., Rozanov, E., Schraner, M., Shepherd, T. G., Shibata, K., Stolarski, R. S., Struthers, H., Tian, W., and Yoshiki, M.: Assessment of temperature, trace species, and ozone in chemistry-climate model simulations of the recent past, J. Geophys. Res., 111, D22308, doi:10.1029/2006JD007327, 2006.

Fleming, E. L., Jackman, C. H., Stolarski, R. S., and Considine, D. B.: Simulation of stratospheric tracers using an improved empirically-based two-dimensional model transport formulation, J. Geophys. Res., 104, 23911-23934, 1999.

Gettelman, A., Hegglin, M. I., Son, S. W., Kim, J. H., Fujiwara, M., Birner, T., Kremser, S., Rex, M., Anel, J. A., Akiyoshi, H., Austin, J., Bekki, S., Braesike, P., Brühl, C., Butchart, N., Chipperfield, M., Dameris, M., Dhomse, S., Garny, H., Hardiman, S. C., Jöckel, P., Kinnison, D. E., Lamarque, J. F., Mancini, E., Marchand, M., Michou, M., Morgenstern, O., Pawson, S., Pitari, G., Plummer, D., Pyle, J. A., Rozanov, E., Scinocca, J., Shepherd, T. G., Shibata, K., Smale, D., Teyssèdre, H., and Tian, W.: Multimodel assessment of the upper troposphere and lower stratosphere: tropics and global trends, J. Geophys. Res, 115, D00M08, doi:10.1029/2009JD013638, 2010.

Grainger, R. G., Lambert, A., Rodgers, C. D., Taylor, F. W., and Deshler, T.: Stratospheric aerosol effective radius, surface-area and volume estimated from infrared measurements, J. Geophys. Res. Atmos., 100, 16507-16518, 1995.

Guo, S., Bluth, G. J. S., Rose, W. I., Watson, I. M., and Prata, A. J.: Re-evaluation of $\mathrm{SO}_{2}$ release of the 15 June 1991 Pinatubo eruption using ultraviolet and infrared satellite sensors, Geochem. Geophy. Geosy., 5, Q04001, doi:10.1029/2003GC000654, 2004.

Heckendorn, P., Weisenstein, D., Fueglistaler, S., Luo, B. P., Rozanov, E., Schraner, M., Thomason, L. W., and Peter, T.: The impact of geoengineering aerosols on stratospheric temperature and ozone, Environ. Res. Lett., 4, 045108, doi:10.1088/17489326/4/4/045108, 2009.

Hervig, M. E., Russell, J. M., Gordley, L. L., Daniels, J., Drayson, S. R., and Park, J. H.: Aerosol effects and corrections in the Halogen Occultation Experiment, J. Geophys. Res., 100, 1067-1079, 1995.

Joshi, M. M. and Shine, K. P.: A GCM Study of Volcanic Eruptions as a Cause of Increased Stratospheric Water Vapor, J. Climate., 16, 3525-3534, 2003.

Kinnison, D. E., Grant, K. E., Connell, P. S., Rotman, D. A., and Wuebbles, D. J.: The chemical and radiative effects of the MountPinatubo eruption, J. Geophys. Res. Atmos., 99, 25705-25731, 1994. 
Kulmala, M., Pirjola, U., and Makela, J. M.: Stable sulphate clusters as a source of new atmospheric particles, Nature, 404, 66-69, 2000.

Labitzke, K. and McCormick, M. P.: Stratospheric temperature increases due to Pinatubo Aerosols, Geophys. Res. Lett., 19, 207210, 1992.

Lambert, A., Grainger, R. G., Remedios, J. J., Rodgers, C. D., Corney, M., and Taylor, F. W.: Measurements of the evolution of the Mt-Pinatubo aerosol cloud by ISAMS, Geophys. Res. Lett., 20, 1287-1290, 1993.

Lambert, A., Grainger, R. G., Remedios, J. J., Reburn, W. J., Rodgers, C. D., Taylor, F. W., Roche, A. E., Kumer, J. B., Massie, S. T., and Deshler, T.: Validation of aerosol measurements from the improved stratospheric and mesospheric sounder, J. Geophys. Res., 101, 9811-9830, doi:10.1029/95JD01702, 1996.

Lambert, A., Grainger, R. G., Rodgers, C. D., Taylor, F. W., Mergenthaler, J. L., Kumer, J. B., and Massie, S. T.: Global evolution of the Mt. Pinatubo volcanic aerosols observed by the infrared limb-sounding instruments CLAES and ISAMS on the Upper Atmosphere Research Satellite, J. Geophys. Res. Atmos., 102, 1495-1512, 1997.

Lanzante, J. R. and Free, M.: Comparison of radiosonde and GCM vertical temperature trend profiles: effects of dataset choice and data homogenization, J. Climate, 21, p. 5417, 2007.

Luo, B., Krieger, U. K., and Peter, T.: Densities and refractive indices of $\mathrm{H}_{2} \mathrm{SO}_{4} / \mathrm{HNO}_{3} / \mathrm{H}_{2} \mathrm{O}$ solutions to stratospheric temperatures, Geophys. Res. Lett., 23, 3707-3710, doi:10.1029/96GL03581, 1996.

McCormick, M. P.: Initial assessment of the stratospheric and climatic impact of the 1991 Mount-Pinatubo eruption - prologue, Geophys. Res. Lett., 19, 149-149, 1992.

Mie, G.: Articles on the optical characteristics of turbid tubes, especially colloidal metal solutions, Ann. Phys., 25, 377-445, 1908.

Minnis, P., Harrison, E. F., Stowe, L. L., Gibson, G. G., Denn, F. M., Doelling, D. R., and Smith, W. L.: Radiative climate forcing by the Mount-Pinatubo eruption, Science, 259, 1411-1415, 1993.

Morgenstern, O., Giorgetta, M. A., Shibata K., Eyring, V., Waugh, D. W., Shepherd, T. G., Akiyoshi, H., Austin, J., Baumgaertner, A. J. G., Bekki, S., Braesicke, P., Brühl, C., Chipperfield, M. P., Cugnet, D., Dameris, M., Dhomse, S., Frith, S. M., Garny, H., Gettelman, A., Hardiman, S. C., Hegglin, M. I., Kinnison, D. E., Lamarque, J. F., Mancini, E., Manzini, E., Marchand, M., Michou, M., Nakamura, T., Nielsen, J. E., Pitari, G., Plummer, D. A., Rozanov, E., Scinocca, J. F., Smale, D., Teyssèdre, H., Toohey, M., Tian, W., and Yamashita, Y.: Review of the formulation of present generation stratospheric chemistry climate models and associated external forcings, J. Geophys. Res., 115, D00M02, doi:10.1029/2009JD013728, 2010.

Rayner, N. A., Parker, D. E., Horton, E. B., Folland, C. K., Alexander, L. V., Rowell, D. P., Kent, E. C., and Kaplan, A.: Global analyses of sea surface temperature, sea ice, and night marine air temperature since the late nineteenth century, J. Geophys. Res., 108, 4407, doi:10.1029/2002JD002670, 2003.

Rosen, J. M.: The vertical distribution of dust to $30 \mathrm{~km}$, J. Geophys. Res., 69, 4673-4676, 1964.

Russell, J. M., Gordley, L. L., Park, J. H., Drayson, S. R., Hesketh, W. D., Cicerone, R. J., Tuck, A. F., Frederick, J. E., Harries, J. E., and Crutzen, P. J.: The halogen occultation experiment,
J. Geophys. Res., 98, 10777-10797, doi:10.1029/93JD00799, 1993.

Russell, P. B., Livingston, J. M., Pueschel, R. F., Bauman, J. J., Pollack, J. B., Brooks, S. L., Hamill, P., Thomason, L. W., Stowe, L. L., Deshler, T., Dutton, E. G., and Bergstrom, R. W.: Global to microscale evolution of the Pinatubo volcanic aerosol derived from diverse measurements and analyses, J. Geophys. Res. Atmos., 101, 18745-18763, 1996.

Sander, S. P., Friedl, R. R., DeMore, W. B., Ravishankara, A. R., Golden, D. M., Kolb, C. E., Kurylo, M. J., Hampson, R. F., Huie, R. E., Molina, M. J., and Moortgat, G. K.: Chemical kinetics and photochemical data for use in stratospheric modeling, Supplement to evaluation 12: Update of key reactions, Evaluation Number 13, JPL Publication 00-3, Jet Propulsion Laboratory, NASA, 2000.

Sato, M., Hansen, J. E., McCormick, M. P., and Pollack, J. B.: Stratospheric aerosol optical depths, 1850-1990, J. Geophys. Res. Atmos., 98, 22987-22994, 1993.

Schraner, M., Rozanov, E., Schnadt Poberaj, C., Kenzelmann, P., Fischer, A. M., Zubov, V., Luo, B. P., Hoyle, C. R., Egorova, T., Fueglistaler, S., Brönnimann, S., Schmutz, W., and Peter, T.: Technical Note: Chemistry-climate model SOCOL: version 2.0 with improved transport and chemistry/microphysics schemes, Atmos. Chem. Phys., 8, 5957-5974, doi:10.5194/acp-8-59572008, 2008.

SPARC: Assessment of Stratospheric Aerosol Properties (ASAP), SPARC Report No. 4, edited by: Thomason, L. and Peter, T., World Climate Research Programme WCRP-124, WMO/TD No. 1295, 2006.

SPARC-CCMVal, 2010: SPARC Report on the Evaluation of Chemistry-Climate Models, edited by: Eyring, V., Shepherd, T. G., and Waugh, D., Tech. rep., SPARC Report No. 5, WCRP-132, WMO/TD-No. 1526, WCRP-132, WMO/TD-No. 1526, 2010.

Stenchikov, G. L., Kirchner, I., Robock, A., Graf, H. F., Antuna, J. C., Grainger, R. G., Lambert, A., and Thomason, L.: Radiative forcing from the 1991 Mount Pinatubo volcanic eruption, J. Geophys. Res. Atm, 103, 13837-13857, 1998.

Stowe, L. L., Carey, R. M., and Pellegrino, P. P.: Monitoring the MtPinatubo aerosol layer with NOAA-11 AVHRR data, Geophys. Res. Lett., 19, 159-162, 1992.

Tabazadeh, A., Toon, O. B., Clegg, S. L., and Hamill, P.: A new parameterization of $\mathrm{H} 2 \mathrm{SO} 4 / \mathrm{H} 2 \mathrm{O}$ aerosol composition: Atmospheric implications, Geophys. Res. Lett., 24, 1931-1934, 1997.

Thomason, L. W.: Observations of a new SAGE-II aerosol extinction mode following the eruption of Mt-Pinatubo, Geophys. Res. Lett., 19, 2179-2182, 1992.

Thomason, L. W., Kent, G. S., Trepte, C. R., and Poole, L. R.: A comparison of the stratospheric aerosol background periods of 1979 and 1989-1991, J. Geophys. Res. Atmos., 102, 3611-3616, 1997 a.

Thomason, L. W., Poole, L. R., and Deshler, T.: A global climatology of stratospheric aerosol surface area density deduced from Stratospheric Aerosol and Gas Experiment II measurements: 1984-1994, J. Geophys. Res. Atmos., 102, 8967-8976, 1997b.

Thomason, L. W.: Toward a combined SAGE II-HALOE aerosol climatology: an evaluation of HALOE version 19 stratospheric aerosol extinction coefficient observations, Atmos. Chem. Phys., 12, 8177-8188, doi:10.5194/acp-12-8177-2012, 2012. 
Weisenstein, D. K., Yue, G. K., Ko, M. K. W., Sze, N. D., Rodriguez, J. M., and Scott, C. J.: A two-dimensional model of sulfur species and aerosols, J. Geophys. Res. Atmos., 102, 1301913035, 1997.

Weisenstein, D. K., Penner, J. E., Herzog, M., and Liu, X.: Global 2D intercomparison of sectional and modal aerosol modules, Atmos. Chem. Phys., 7, 2339-2355, doi:10.5194/acp-7-2339-2007, 2007.
Wurl, D., Grainger, R. G., McDonald, A. J., and Deshler, T.: Optimal estimation retrieval of aerosol microphysical properties from SAGE II satellite observations in the volcanically unperturbed lower stratosphere, Atmos. Chem. Phys., 10, 4295-4317, doi:10.5194/acp-10-4295-2010, 2010. 